\title{
Prevalência de trauma dental em crianças e adolescentes atendidos no NEPTI da FOUFBA
}

\author{
Vaipscia Bitencourt Dantas*; Alessandra Castro Alves**; Ana Isabel Fonseca Scavuzzi***
}
* Graduada pela Faculdade de Odontologia, Universidade Federal da Bahia
** Professora Associada, Faculdade de Odontologia, Universidade Federal da Bahia; Professora Adjunta; Curso de Odontologia, Universidade Estadual de Feira de Santana
*** Professora Titular, Curso de Odontologia, Universidade Estadual de Feira de Santana

Recebido em 15/05/2019. Aprovado em 20/06/2019.

\begin{abstract}
RESUMO
A indissociabilidade entre ensino, pesquisa e extensão é almejável para a oferta do ensino odontológico de qualidade. O estudo teve por objetivo determinar o perfil dos pacientes atendidos no Núcleo de Extensão/Pesquisa em Trauma Dental na Faculdade de Odontologia da Universidade Federal da Bahia. A pesquisa foi realizada com 86 pacientes de ambos os sexos, com idade entre 0 e 14 anos, apresentando lesões alvéolo-dentárias. Dois indivíduos já haviam sido atendidos anteriormente, retornando com novo trauma, totalizando 88 episódios de traumatismos. Os dados foram coletados de março de 2016 a janeiro de 2018 e as variáveis avaliadas foram idade e sexo do paciente, dentes afetados, tipo, etiologia, classificação e local onde ocorreu o trauma. Dos 86 pacientes $58,1 \%$ eram meninos e 41,9\% meninas, com idades variando entre 1 e 14 anos, com média de 5,5 ( $\pm 3,7)$ anos. Na maioria dos casos um dente foi afetado e os incisivos centrais superiores foram os mais atingidos. Nos dentes decíduos a subluxação foi o trauma mais frequente nos tecidos de suporte e a fratura coronária com exposição pulpar nos tecidos dentais. Nos dentes permanentes a avulsão foi o trauma mais frequente nos tecidos de suporte e as fraturas do esmalte e da dentina nos tecidos dentários. Foi possível caracterizar o perfil dos pacientes que foram tratados com lesões dentárias no projeto, permitindo aos cirurgiões-dentistas conhecer a população de risco da região, as principais causas e os traumas mais frequentes.
\end{abstract}

Descritores: Relações Comunidade-Instituição. Educação Superior. Epidemiologia. Traumatismos dentários.

\section{INTRODUÇÃO}

A LDB - Lei de Diretrizes e Bases da Educação $^{1}$, no capítulo IV sobre a Educação
Superior no Brasil, estabelece no artigo 43, inciso VII, como finalidade da educação superior no país "promover a extensão, aberta à participação da 
população, visando à difusão das conquistas e benefícios resultantes da criação cultural e da pesquisa científica e tecnológica geradas na instituição". A Lei 13.005 de 25 de junho de 2014 aprovou o Plano Nacional de Educação (PNE)2, com vigência de 10 anos, estabelecendo 20 metas para serem cumpridas neste prazo. A meta 12 do PNE trata da educação superior, constituindo a estratégia 12.7 “assegurar, no mínimo, $10 \%$ (dez por cento) do total de créditos curriculares exigidos para a graduação em programas e projetos de extensão universitária, orientando sua ação, prioritariamente, para áreas de grande pertinência social’. O glossário dos Instrumentos de Avaliação Externa do Ministério da Educação (MEC) $)^{3}$, define a extensão como o "processo interdisciplinar educativo que promove a interação entre a instituição de ensino superior (IES) e os outros setores da sociedade, aplicando o desenvolvimento científico e tecnológico junto aos agentes do meio externo".

Neste cenário, a Faculdade de Odontologia da Universidade Federal da Bahia (FOUFBA) aprovou, em fevereiro de 2015, a implantação da proposta 8863 - projeto de ação permanente sob o título "Projeto Integrado de Atendimento aos Traumatismos na Infância e Adolescência", denominado como Núcleo de Extensão/Pesquisa em Trauma Dental da FOUFBA (NEPTI FOUFBA), com o objetivo de atender crianças e adolescentes que buscassem o serviço na faculdade por serem vítimas de traumatismos dentários.

Os traumatismos dentários são um dos problemas de saúde pública que mais acometem crianças e adolescentes, representando situações frequentemente presentes no atendimento na Odontologia e na Odontopediatria ${ }^{4-7}$. O trauma pode ser originário de ato de violência ou acidental. Os de causas acidentais estão relacionados com o estágio de desenvolvimento da criança e o seu comportamento. $\mathrm{O}$ desenvolvimento neuromuscular e intelectual faz com que as crianças ampliem a visão sobre o ambiente e passem a explorá-lo de forma mais ampliada adquirindo autonomia e tornando-se mais vulneráveis aos acidentes, justificando, assim, a alta prevalência de traumatismos dentários nessa fase do desenvolvimento do indivíduo ${ }^{8}$.

Muitos estudos vêm sendo realizados no mundo sobre prevalência de injúrias dentárias decorrentes de trauma e, no Brasil, a produção científica tem crescido sobre esta temática ${ }^{8,12}$. Azami-Aghdash, et al. ${ }^{5}$, em revisão sistemática sobre a epidemiologia dos traumatismos, observou que, de 44 artigos selecionados sobre o tema, 16 foram produzidos no Brasil e os outros 28 trabalhos foram de países diversos, demostrando um alto número de casos em crianças e adolescentes. Os estudos epidemiológicos relacionados ao trauma dental fornecem o conhecimento do perfil de risco para esse tipo de lesão, baseados em variáveis tais como as principais etiologias, dentes mais afetados, gênero, idade do paciente, tipo de trauma mais frequente e os aspectos socioeconômicos relacionados ${ }^{5,9}$.

A etiologia do traumatismo dentário mais frequentemente encontrada nestes estudos são as quedas da própria altura, atingindo os dentes decíduos $^{5-7,10}$. Nos dentes permanentes as causas mais frequentes são esportes e atividades recreativas ${ }^{6,11,12}$. A região anterossuperior é a mais atingida por trauma, afetando principalmente os incisivos centrais ${ }^{5,6,10,12-17}$. Fatores biológicos, tais como a falta do selamento labial e overjet acentuado podem colaborar para a maior incidência de trauma nesta região. Alguns estudos concordam com essa associação, mas outros não encontraram significância estatística dos fatores biológicos na incidência dos traumas ${ }^{11,14}$. Em relação ao gênero, nas lesões envolvendo dentes decíduos, a literatura aponta que não há uma diferença significativa entre meninos e meninas ${ }^{6,15,18,19}$. Contudo, para os dentes permanentes, os meninos apresentam uma taxa maior de acometimento, muito em decorrência do 
tipo de atividade recreativa desenvolvida nessa fase $^{7,10,16}$. A lesão mais frequentemente encontrada nos tecidos de sustentação é a subluxação ${ }^{13,23}$, enquanto as fraturas de esmalte se encontram como as mais prevalentes dentre as lesões do tecido dentário ${ }^{8,13,21-23}$.

Essas variáveis sugerem um perfil de risco que deve ser conhecido pelos profissionais de Odontologia para que possam dar orientação sobre formas de prevenção e intervir de forma rápida e eficaz no atendimento, por se tratar de crianças e adolescentes, grupo que demanda maior habilidade nas ações, principalmente em situações de urgência $^{24}$. Em caso de lesões dentárias, a intervenção correta e a busca por atendimento odontológico, pelo responsável pela criança/adolescente, devem ser imediatas. $\mathrm{O}$ atendimento breve é importante para um melhor prognóstico $^{14,19}$. Muitos pais/responsáveis buscam os serviços médicos de urgência imediatamente após o ocorrido, outros negligenciam os traumatismos por não acharem necessária tal brevidade no atendimento. Normalmente, esta negligência no atendimento ocorre quando as alterações físicas são indetectáveis por leigos, quando não há queixas de dor, quando entendem que o trauma teve um impacto de baixa intensidade e, ainda, quando acometem os dentes decíduos $^{5,6,11,18,19}$. O profissional de odontologia somente é acionado quando o dente afetado já está comprometido pela sequela, sendo, muitas vezes, inviável sua manutenção no arco dentário ${ }^{18}$.

Mesmo com a compreensão e conhecimento dos fatores de risco associados ao traumatismo dentário, ainda não há uma real estratégia de prevenção, já que comumente são decorrentes de casualidades ${ }^{17}$. Como sugestão para prevenir os traumatismos dentoalveolares, pode-se indicar uma melhor supervisão por parte dos pais/responsáveis da criança e o uso de protetores bucais durante atividades esportivas ou recreativas que envolvam maior contato físico entre os indivíduos ${ }^{15}$.
O NEPTI FOUFBA está localizado em Salvador, dentro da própria instituição, e atende crianças e adolescentes vítimas de traumatismos dentoalveolares por demanda livre ou por encaminhamento de hospitais, unidades de pronto atendimento, unidade básicas de saúde, clínicas odontológicas particulares, dentre outros estabelecimentos de saúde. O NEPTI FOUFBA atende situações de urgências e ainda as crianças e adolescentes que sofreram traumatismos e não obtiveram o atendimento imediato. Estes últimos apresentam as sequelas decorrentes dessas lesões. Todos recebem acompanhamento por longo prazo de acordo com cada tipo de trauma. Em sua maioria, esses pacientes que procuram atendimento no núcleo são de nível socioeconômico baixo, por se tratar de uma IES pública que atende, principalmente, pacientes cadastrados no Sistema Único de Saúde (SUS).

Desta forma, o objetivo deste estudo é determinar o perfil dos atendimentos realizados no NEPTI FOUFBA, avaliando a idade e sexo do paciente, dentes afetados, tipo etiologia, classificação e local onde ocorreu o trauma, possibilitando aos profissionais de Odontologia conhecerem a população em risco na região.

\section{METODOLOGIA}

Este estudo foi do tipo corte transversal realizado com os dados oriundos dos atendimentos ocorridos no NEPTI FOUFBA, no período de março de 2016 a janeiro de 2018. Consiste em um recorte de um projeto maior que foi submetido e aprovado pelo Comitê de Ética em Pesquisa da FOUFBA (CAAE: 66611217.0.0000.5024).

O grupo de estudo foi formado por todos os pacientes que procuraram o serviço no período acima relatado. As informações individuais dos pacientes infantis e adolescentes atendidos no projeto, bem como seus dados clínicos e radiográficos, foram obtidos por meio da consulta ao registro em um prontuário odontológico, 
desenvolvido especificamente para este fim. A calibração deste prontuário foi realizada através de um estudo piloto anteriormente à realização desta pesquisa. Os dados foram protegidos através dos Termos de Consentimento e Assentimento Livre e Esclarecido, ambos assinados pelos pais/ responsáveis pela criança, respectivamente.

$\mathrm{O}$ registro do tipo de trauma seguiu a classificação de Andreasen et al. ${ }^{22}$ É importante esclarecer que um mesmo dente pode ter o registro de um ou mais tipos de traumatismo, podendo afetar os tecidos dentários ou de sustentação exclusivamente, ou todos os tecidos; concomitantemente. A etiologia foi dividida em quedas da própria altura, atividades recreativas (andar de bicicleta, skate, piscina, pula-pula e futebol, dentre outros), choque com objeto estático (mesa, cadeira, janela, dentre outros) e violência. $\mathrm{O}$ local de ocorrência foi classificado como em casa, rua/praça, escolas/creches e outros (parques aquáticos, quadra de esportes, igrejas, lojas, bancos, dentre outros estabelecimentos).

Alguns dados são classificados como não informados pelo responsável, pois no NEPTI FOUFBA, além do atendimento imediato, são acolhidos pacientes que procuram o serviço dias, meses ou até anos após ocorrência de traumas dentários e o responsável, muitas vezes, não se recorda da história ou não sabe informar o tipo de traumatismo sofrido.

Os dados foram armazenados em um banco de dados no programa Excel e analisados para possibilitar o tratamento estatístico, sendo realizada análise descritiva.

\section{RESULTADOS}

No período foram atendidos 86 pacientes, sendo que 2 retornaram com um novo trauma. Sendo assim, a amostra foi composta por um total de 88 episódios de traumatismos dentários em 86 crianças e adolescentes.

A média de idade observada nos 86 pacientes foi de 5,5 anos $( \pm 3,7)$, havendo um maior número de traumas em crianças na faixa etária de escolares de 1 a 9 anos, com maior número de pacientes acometidos por trauma aos 2 anos de idade (18\%). A idade mínima registrada foi de 1 ano e máxima, de 14 anos (gráfico 1).

Dos 86 pacientes atendidos, 50 indivíduos eram do sexo masculino $(58,1 \%)$ e 36 , do sexo feminino (41,9\%). Foi observado, tanto em dentes decíduos como nos permanentes, o maior número de meninos atingidos por trauma quando comparados às meninas. Os três registros de trauma somente em tecidos moles ocorreram nas meninas, conforme pode ser observado no gráfico 2 .

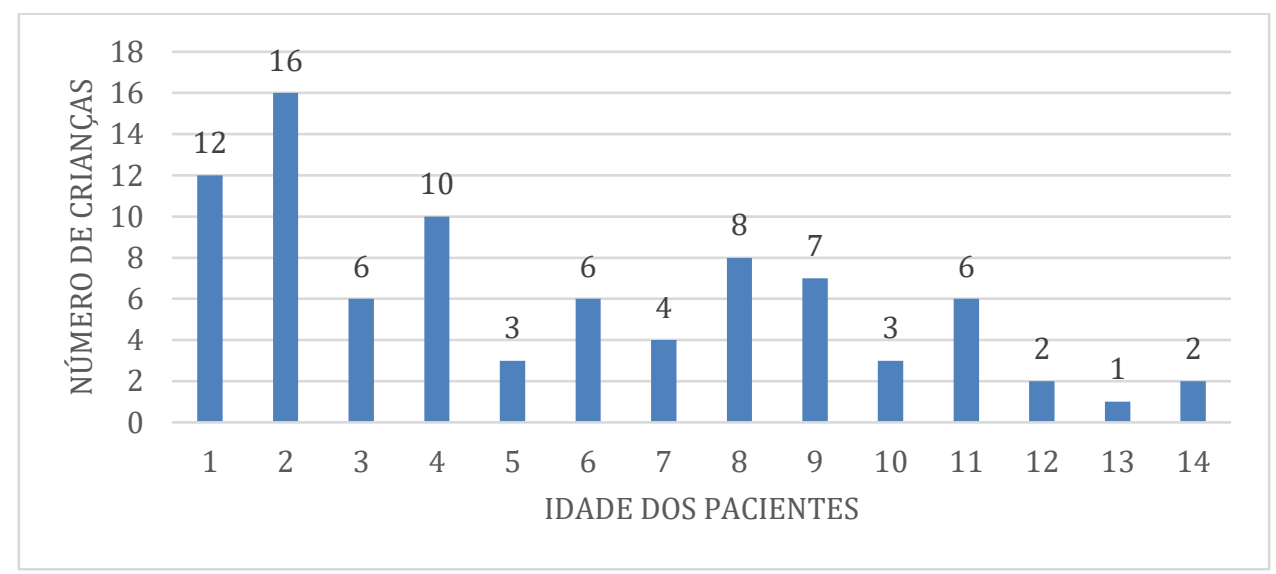

Gráfico 1. Idade dos pacientes atendidos no NEPTI FOUFBA quando sofreram traumatismos dentais 


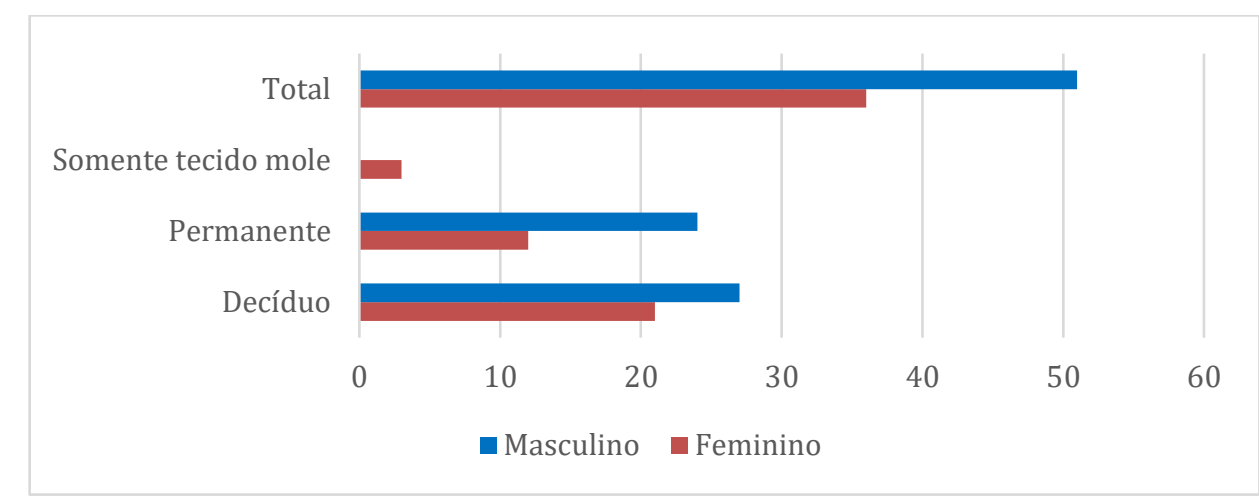

Gráfico 2. Gênero dos pacientes atendidos no NEPTI FOUFBA de acordo com tipo de dente acometido e tecidos moles

A queda da própria altura foi a principal causa do traumatismo em dentes decíduos (72,3\%), seguida por atividades recreativas $(12,8 \%)$, choque com objeto $(6,4 \%)$ e violência $(8,5 \%)$. Nos dentes permanentes $50 \%$ dos pacientes tiveram como etiologia as atividades recreativas, seguida de quedas $(33,3 \%)$, choque com objeto $(8,3 \%)$ e atos de violência $(8,3 \%)$. Dos traumas atingindo apenas tecidos moles, 66,7\% foram decorrentes de atividades recreativas e os outros $33,3 \%$ estiveram relacionados às quedas (tabela 1 ).

Os locais de ocorrência do trauma mais frequentes foram o ambiente domiciliar $(76,6 \% \mathrm{em}$ dentes decíduos, 38,9\% em dentes permanentes e $66,7 \%$ em tecidos moles), na rua ( $14,9 \%$ em dentes decíduos e $30,6 \%$ em dentes permanente) e na escola $(6,4 \%$ nos dentes decíduos e $11,1 \%$ nos dentes permanentes) (tabela 1).

Quanto ao número de dentes afetados, podese observar apenas um dente afetado pela injúria traumática em $55 \%$ dos pacientes, seguido pelo trauma a dois dentes, em $37 \%$ do total. Foram atingidos 127 dentes entre decíduos e permanentes. Os incisivos centrais superiores foram os dentes mais afetados (87\%), seguido pelos incisivos laterais superiores (10\%). Não houve registro de incisivo lateral inferior na amostra estudada, conforme pode ser observado nos gráficos 3 e 4 .
Foram registrados 132 traumatismos em unidades dentárias, sendo 56 dentes permanentes e 76 decíduos, e mais 3 traumatismos envolvendo apenas tecidos moles. Registraram-se 67 (49,6\%) traumas em tecidos de suporte, $57(42,2 \%)$ em tecidos dentários, 3 casos onde só houve tecido mole afetado $(2,2 \%)$ e 8 casos em que não havia registro do tipo de trauma no prontuário $(5,9 \%)$.

Nos dentes decíduos atingidos $(n=76)$, foram registrados $25 \%$ de casos de subluxação, seguidos de avulsão e luxação lateral, ambos com 10,5\% quando os tecidos de suporte estavam envolvidos no trauma. Nos tecidos dentários envolvendo os dentes decíduos, 9 casos de fraturas coronárias com exposição pulpar (11,8\%), 8 fraturas em esmalte $(10,5 \%), 4$ fraturas radiculares $(5,3 \%)$ e nenhum caso de fratura em esmalte e dentina registrados nessa amostra, conforme a tabela 2 .

Nos permanentes, em tecido de suporte, houve maior frequência de avulsão, com 10 casos (17,9\%), seguido de luxação lateral, com 4 registros $(7,1 \%)$, e subluxação, com 3 registros (5,4\%). Nos tecidos dentários, 22 fraturas em esmalte e dentina (39,3\%), seguidas de 8 fraturas em esmalte $(14,3 \%)$ e 6 fraturas coronárias com exposição pulpar (10,7\%). Não foram evidenciadas fraturas alveolares ou radiculares associadas aos dentes permanentes (tabela 2). 
Tabela 1. Etiologia e local dos traumas de acordo com tipo de dente acometido e tecidos moles $(\mathrm{n}=86)$

\begin{tabular}{lcccccc}
\hline & \multicolumn{2}{c}{ Decíduo $(\mathbf{n = 4 7})$} & \multicolumn{2}{c}{ Permanente $(\mathbf{n = 3 6})$} & \multicolumn{2}{c}{$\begin{array}{c}\text { Somente } \\
\text { Tecido Mole (n=3) }\end{array}$} \\
\hline Etiologia & $\mathrm{n}$ & $\%$ & $\mathrm{n}$ & $\%$ & $\mathrm{n}$ & $\%$ \\
Queda & 34 & $72,3 \%$ & 12 & $33,3 \%$ & 1 & $33,3 \%$ \\
Atividade recreativa & 6 & $12,8 \%$ & 18 & $50,0 \%$ & 2 & $66,7 \%$ \\
Choque com objeto & 3 & $6,4 \%$ & 3 & $8,3 \%$ & 0 & $0,0 \%$ \\
$\quad$ Violência & 4 & $8,5 \%$ & 3 & $8,3 \%$ & 0 & $0,0 \%$ \\
Local do trauma & & & & & & \\
Casa & 36 & $76,6 \%$ & 14 & $38,9 \%$ & 2 & $66,7 \%$ \\
Rua & 7 & $14,9 \%$ & 11 & $30,6 \%$ & 0 & $0,0 \%$ \\
Escola & 3 & $6,4 \%$ & 4 & $11,1 \%$ & 0 & $0,0 \%$ \\
Outros & 0 & $0,0 \%$ & 5 & $13,9 \%$ & 1 & $33,3 \%$ \\
Sem informação & 1 & $2,1 \%$ & 2 & $5,6 \%$ & 0 & $0,0 \%$ \\
\hline
\end{tabular}

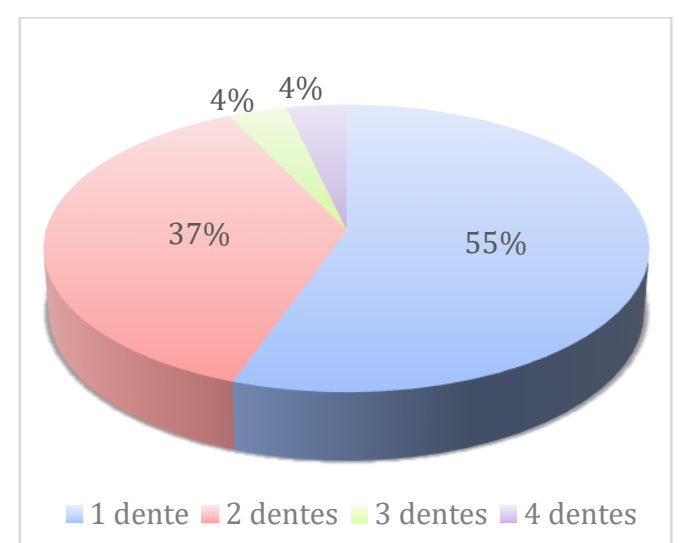

Gráfico 3. Número de dentes envolvidos no trauma $(\mathrm{n}=83)$

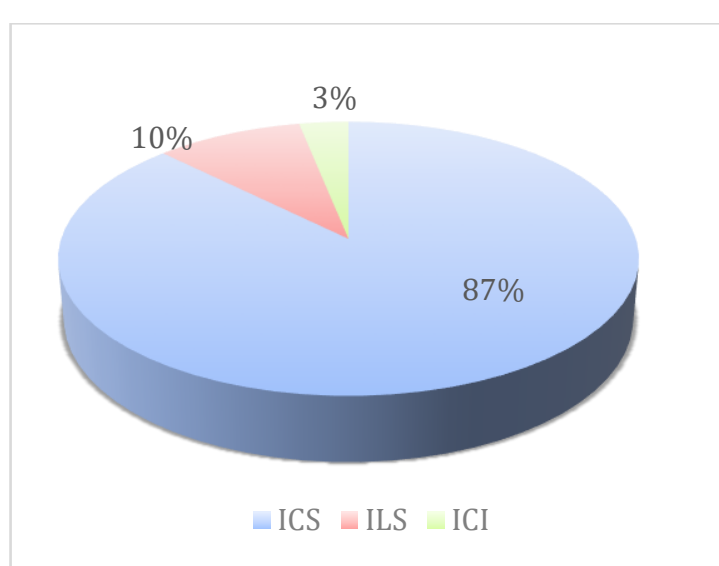

Gráfico 4. Grupo de dentes mais afetados no trauma $(n=127)$

Tabela 2. Tipo de traumatismo relacionado ao tipo de dente $(n=132)$

\begin{tabular}{lcccc} 
Tipo de trauma (n=132) & $\begin{array}{c}\text { Decíduo } \\
\mathbf{n}\end{array}$ & $\begin{array}{c}(\mathbf{n = 7 6}) \\
\mathbf{\%}\end{array}$ & $\begin{array}{c}\text { Permanente } \\
\mathbf{n}\end{array}$ & $\begin{array}{l}(\mathbf{n}=\mathbf{5 6}) \\
\mathbf{\%}\end{array}$ \\
\hline Tecido Sustentação & & & & \\
$\quad$ Avulsão & 8 & $10,5 \%$ & 10 & $17,9 \%$ \\
Luxação lateral & 8 & $10,5 \%$ & 4 & $7,1 \%$ \\
Luxação intrusiva & 6 & $7,9 \%$ & 1 & $1,8 \%$ \\
Luxação extrusiva & 2 & $2,6 \%$ & 1 & $1,8 \%$ \\
Subluxação & 19 & $25,0 \%$ & 3 & $5,4 \%$ \\
Fratura alveolar & 5 & $6,6 \%$ & 0 & $0,0 \%$ \\
Tecido Dental & & & & \\
Fratura em esmalte & 8 & $10,5 \%$ & 8 & $14,3 \%$ \\
Fratura em esmalte e dentina & 0 & $0,0 \%$ & 22 & $39,3 \%$ \\
Fratura de coroa com exposição pulpar & 9 & $11,8 \%$ & 6 & $10,7 \%$ \\
Fratura radicular & 4 & $5,3 \%$ & 0 & $0,0 \%$ \\
Sem informação & 7 & $9,2 \%$ & 1 & $1,8 \%$ \\
\hline
\end{tabular}




\section{DISCUSSÃO}

A indissociabilidade entre ensino, pesquisa e extensão é requisito para oferta do ensino superior de qualidade. A promoção da extensão universitária aberta à participação da população, a curricularização da extensão e as suas ações aplicadas para os diversos setores da comunidade intencionam promover um grande e positivo impacto social ${ }^{1-3}$. Por sua vez, a pesquisa científica oriunda destas ações, com envolvimento dos discentes e docentes do ensino superior, resultam no perfeito e almejado tripé ensino-pesquisaextensão para a instituição promotora.

Neste contexto, o NEPTI FOUFBA tem o objetivo de documentar, diagnosticar, tratar e proservar os casos de traumatismos dentários que atingem crianças e adolescentes encaminhados ao serviço ou que o procuram por livre demanda. Outrossim, os traumatismos dentários são considerados um dos principais problemas de saúde bucal com alta incidência em crianças e adolescentes. Assim, como consequência desta ação extensionista na FOUFBA, haverá também produção científica com vistas a caracterizar essa população que busca atendimento de urgência ou tardio decorrente de um traumatismo dental. Esses resultados podem embasar o desenvolvimento de políticas de prevenção ao trauma como também auxiliar nas tomadas de decisões clínicas durante o atendimento odontológico.

Neste levantamento, houve o registro de 86 pacientes com duas recorrências de traumas registrados, totalizando 88 episódios de traumatismos infantojuvenis. Nesta amostra, a faixa etária com maior prevalência de trauma foi a de 1 a 9 anos de idade, período este de desenvolvimento, quando as crianças começam a dar os primeiros passos e a explorar o ambiente. $\mathrm{Na}$ idade dos escolares, as atividades ligadas ao lazer, esportes e brincadeiras contribuíram para uma alta frequência de traumatismos dos 6 aos 11 anos de idade. A literatura aponta que crianças na faixa de
1 a 3 anos estão mais sujeitas às quedas pelas características próprias do desenvolvimento, tais como curiosidade e falta de coordenação motora ${ }^{8}$. Campos et al. ${ }^{6}$ encontraram a faixa etária de 1 a 4 anos como a mais afetada em dentes decíduos. Kramer et $a l .{ }^{13}$ encontraram no seu estudo com crianças de 3 a 12 anos, a faixa etária de 7 a 9 anos com maior número de registros de traumatismo dentoalveolar. O gênero masculino apresentou mais casos de traumatismos quando comparado ao gênero feminino neste estudo.

Os traumatismos podem ter causa acidental (quedas, atividades recreativas, choque com algum objeto) ou são decorrentes de atos de violência. Nesse estudo, houve registros decorrentes da violência em $8,5 \%$ dos pacientes com trauma em dentes decíduos e 8,3\%, nos dentes permanentes. A prevalência de crianças e adolescentes acometidas por traumatismos dentários causados por atos violentos é alta. Das lesões investigadas no Instituto Médico Legal, em Feira de Santana (BA), $39,2 \%$ foram lesões dentárias oriundas da violência $^{23}$. No estudo de Malta et $_{\text {al. }}{ }^{7}$, a região de cabeça e pescoço foi a mais atingida por traumas decorrentes de acidentes, na faixa etária de 2 a 5 anos de idade, e relacionadas a atos violentos, na faixa de 6 a 9 anos. O estudo de Carvalho et al. ${ }^{24}$ também traz a região de cabeça e pescoço como área de alta prevalência de lesões quando comparada às outras regiões do corpo. Esta área está diretamente relacionada ao trabalho do cirurgião-dentista, que deve notificar situações sugestivas de violência.

Os traumatismos acidentais estão relacionados com o estágio de desenvolvimento da criança e seu comportamento ${ }^{8}$. De acordo com diversos autores, as quedas são a causa mais frequente de traumas aos dentes decíduos ${ }^{5-7,10}$, corroborando os resultados encontrados no presente estudo, em que as quedas foram responsáveis pelo trauma a dentes decíduos em $72,3 \%$ dos pacientes. Os acidentes decorrentes de 
atividades recreativas como bicicleta, triciclos não motorizados, esportes e outras brincadeiras são as principais causas de traumatismos dentoalveolares que atingem os dentes permanentes em crianças mais velhas ${ }^{6,10}$. Nesse estudo, para os dentes permanentes, os traumas decorrentes das atividades recreativas foram os mais frequentes $(50 \%)$.

Segundo alguns autores, o ambiente doméstico é o principal local onde ocorrem as injúrias traumáticas atingindo os dentes decíduos ${ }^{5-}$ 7,10, sendo também observada, nessa amostra, a maior porcentagem de traumatismos ocorridos em casa $(76,6 \%$ em dentes decíduos, 38,9\% em dentes permanentes e 66,7\% em tecidos moles). Quando os dentes permanentes foram os afetados pelo trauma, os acidentes ocorridos em casa $(38,9 \%) \mathrm{e}$ na rua $(30,6 \%)$ apresentaram valores próximos. Este fato se deve à ampliação do ambiente para a prática de atividades recreativas pela criança e pelo adolescente em desenvolvimento ${ }^{8}$. Entretanto, a falta de padronização e categorização dessas variáveis, nos vários estudos realizados, dificulta e restringe comparações entre os resultados.

Os incisivos centrais superiores foram os mais afetados pelo trauma, corroborando os achados encontrados em outros estudos, que observaram ser a região anterossuperior a mais atingida, especialmente os incisivos centrais ${ }^{5,6,10,12-}$ 17. A maioria dos traumas acometeu um dente (54\%), de acordo com achados em outros estudos $^{13,14,19}$, e, em seguida, dois (36\%). Guedes et $a l .{ }^{16}$ e Pereira et al. ${ }^{10}$ encontraram dois ou mais dentes afetados em seus estudos, discordando dos resultados encontrados nessa amostra.

Foi observado, em dentes decíduos, que a subluxação $(25 \%)$ foi o trauma mais frequente aos tecidos de suporte e, no tecido dentário, foram as fraturas de coroa com exposição pulpar $(11,8 \%)$, seguido das fraturas em esmalte (10,5\%). Esses resultados são semelhantes aos encontrados na literatura, demostrando que os traumas mais frequentes aos dentes decíduos, envolvendo tecidos de suporte, são as subluxações e, nos tecidos dentários, as fraturas em esmalte , $^{5,9,10,14,18,19}$. Jung et $a{ }^{4}{ }^{4}$ também observaram que as fraturas coronárias com exposição pulpar e as subluxações foram os tipos traumáticos que mais afetaram os tecidos dentários e de suporte, respectivamente. A alta incidência de subluxações na dentição decídua se deve à elevada resiliência do osso, que dissipa o impacto do trauma, protegendo a estrutura dental ${ }^{20}$.

$\mathrm{Na}$ amostra dos dentes permanentes, a avulsão $(17,9 \%)$ foi o tipo de trauma mais frequentemente encontrado envolvendo tecidos de suporte; no trauma aos tecidos duros, foram as fraturas em esmalte e dentina (39,3\%). Em dentes permanentes traumatizados, as fraturas em esmalte são as lesões mais frequentemente encontradas na literatura ${ }^{5,9,10}$, discordando do resultado desta pesquisa.

Algumas informações colhidas do paciente e do responsável relativas à forma como as lesões acorreram, dados importantes para a conclusão diagnóstica, podem ser imprecisas. Isso é possível ocorrer, pois o responsável pela criança e pelo adolescente muitas vezes não lembra ou não sabe ao certo como ocorreu o trauma. Alguns pacientes foram atendidos quando já existiam sinais e/ou sequelas de traumatismos antigos. Alteração cromática, reabsorção externa, calcificações, necrose pulpar, mobilidade e mudança da posição do dente no arco foram algumas sequelas observadas durante o exame clínico-radiográfico. Faz-se necessário que os pais estejam atentos e procurem os serviços odontológicos de pronto atendimento o mais rapidamente possível para evitar ou minimizar possíveis sequelas.

Apesar de inexistirem dados nesta pesquisa sobre a condição socioeconômica, demográfica e de escolaridade dos pais/responsáveis dos pacientes atendidos no NEPTI FOUFBA, foi possível observar que a maioria deles se encontra em situação socioeconômica vulnerável e tem baixa escolaridade. Ainda tendo acesso ao 
tratamento, muitos não procuram atendimento pósocorrência dos traumatismos. Segundo Kramer et $a l{ }^{13}$, fatores como baixa escolaridade e idade materna avançada apresentaram alta relação com a baixa adesão ao tratamento dos traumatismos e a pouca importância atribuída ao acompanhamento dos casos.

Neste estudo, foi possível traçar o perfil dos pacientes atendidos no NEPTI FOUFBA, porém, por se tratar de amostra de pacientes de um centro de referência, os resultados podem não ser representativos da população. Esta pesquisa reflete o papel do NEPTI FOUFBA na promoção da extensão universitária aberta ao atendimento e da participação da população da cidade do Salvador (Bahia).

\section{CONCLUSÃO}

Com base nos resultados encontrados, foi possível traçar o perfil dos pacientes atendidos no NEPTI FOUFBA. A idade mais acometida foi a de 2 anos (na faixa etária entre 1 a 9 anos); meninos sofreram mais traumatismos alvéolodentários quando comparados às meninas; os dentes mais afetados foram os incisivos centrais superiores e, na maioria dos casos, foi atingindo um único dente. As quedas da própria altura e as atividades recreativas foram as causas mais comuns de traumatismos dentais, os quais ocorreram com maior frequência no ambiente doméstico, resultando, majoritariamente, em subluxação, fraturas em esmalte e fratura coronária com exposição pulpar de dentes decíduos. Nos dentes permanentes, a avulsão e as fraturas em esmalte e dentina foram as mais frequentes.

\section{ABSTRACT \\ Prevalence of dental trauma in children and adolescents assisted at NEPTI at FOUFBA}

The inseparability between teaching, research and extension is desirable for the provision of quality dental education. This study determined the profile of patients assisted at the Extension/Research Unit in Dental Trauma at the Dental School of UFBA. The study was conducted on 86 patients of both genders, aged 0 to 14 years, presenting dentoalveolar lesions. Two individuals had already been previously treated and returned with a new trauma, adding up to 88 episodes of trauma. Data were collected from March 2016 to January 2018 and the variables evaluated were age and gender of the patient, affected teeth, type, etiology, classification and place where the trauma occurred. Among the 86 patients, $58.1 \%$ were boys and $41.9 \%$ girls, with age ranging from 1 to 14 years with mean of $5.5( \pm 3.7)$ years. In most cases one tooth was affected, and the upper central incisors were the most affected. In primary teeth, subluxation was the most frequent trauma in supporting tissues and coronal fracture with pulp exposure in dental tissues. In permanent teeth, avulsion was the most frequent in supporting tissues and enamel and dentin fractures in dental tissues. It was possible to characterize the profile of patients treated with dental injuries in the project, enabling the dentists to know the risk population of the region, the main causes and the most frequent traumas.

Descriptors: Community-Institutional Relations. Education, Higher. Epidemiology. Tooth Injuries.

\section{REFERÊNCIAS}

1. Brasil. Lei $\mathrm{n}^{\circ} 9.394$, de 20 de dezembro de 1996. Estabelece as Diretrizes e Bases da Educação Nacional. Diário Oficial da União 23 dez 1996.

2. Brasil. Ministério da Educação. Lei $n^{\circ}$ 13.005, de 25 de junho de 2014. Aprova o Plano Nacional de Educação - PNE e dá outras providências. Diário Oficial da União 26 jun 2014.

3. Ministério da Educação. Avaliação in loco. Glossário dos Instrumentos de Avaliação Externa de Cursos de Graduação. 3 ed. Agosto 2019.

4. Jung CP Tsai AI, Chen CM. A 2-year 
retrospective study of pediatric dental emergency visits at a hospital emergency center in Taiwan. Biomed J.2016;39(3): 207-13.

5. Azami-Aghdash S, Azar FE, Azar FP, Rezapour A, Moradi-Joo M, Moosavi A, et al. Prevalence, etiology, and types of dental trauma in children and adolescents: systematic review and meta-analysis. Med J Islam Repub Iran. 2015;29(4):234.

6. Campos V, Lenzi MM, Marçal SLM, Andrade MRTC, De Marsillac MDWS. Traumatismo nos dentes decíduos anteriores: Estudo retrospectivo do Projeto de Extensão em Traumatologia Dentária da Faculdade de Odontologia da Universidade Estadual do Rio de Janeiro. Interagir: pensando a extensão 2017; (22), 46-60.

7. Malta DC, Mascarenhas MDM, Silva MMAD, Carvalho MGOD, Barufaldi LA, Avanci JQ, et al. The occurrence of external causes in childhood in emergency care: epidemiological aspects Brazil 2014. Cien Saúde Colet. 2016;21(12): 3729-3744.

8. Feldens CA, Kramer PF. Traumatismo na dentição decídua: Prevenção. Diagnóstico e tratamento. $2^{\mathrm{a}}$ ed. São Paulo: Santos, 2013.

9. Rodrigues AS, Castilho T, Antunes LAA, dos Santos Antunes L. Perfil Epidemiológico dos traumatismos dentários em crianças e adolescentes no Brasil. J Health Sci. 2015;17(4): 267-78.

10. Pereira AC, Neto C, Lima TFR, Zaia AA, Soares ADJ. Atendimentos realizados no Serviço de Traumatismos Dentários da FOPUNICAMP durante o período de dois anos. Rev Faculd Odonto Univ Passo Fundo. 2016;21(1):09-14.

11. Keels, MA. Management of dental trauma in a primary care setting. Pediatrics. 2014;133(2):e466-e76.

12. Moreira RF, Figueiredo RG, Colodetti H,
Miranda MSD. Traumatismo dentário na adolescência $\mathrm{x}$ atividade física. Como orientar e prevenir? Rev Dent Press Estet. 2015;12(3):56-60.

13. Kramer PF, Feldens CA., Ruschel HC, Ferreira SH, Senna RA, Vargas-Ferreira F. Traumatismos alveolodentários e fatores associados em crianças assistidas em um curso de Odontologia no sul do Brasil. Stomatos. 2018;23(45):28-38.

14. Piovesan C, Guedes RS, Casagrande L, Ardenghi TM. Socioeconomic and clinical factors associated with traumatic dental injuries in Brazilian preschool children. Braz Oral Res. 2012;26(5):464-70.

15. Corrêa-Faria P, Paixão-Gonçalves S, Paiva SM, Ramos-Jorge ML, Pordeus IA. Casecontrol study on factors associated with crown fractures in the primary dentition. Braz Oral Res. 2015;29(1):1-6.

16. Guedes OA, Alencar AHGD, Lopes LG, Pécora JD, Estrela C. A retrospective study of traumatic dental injuries in a Brazilian dental urgency service. Braz Dent J. 2010;21(2):153-7.

17. Bitencourt SB, Cunha AIDO, Oliveira DWRD, Jardim ATB. Abordagem terapêutica das fraturas dentárias decorrentes do traumatismo dentário. Rev. Odontol. Araçatuba (Online). 2015; 36(1): 24-9.

18. Berti GO, Hesse D, Bonifácio CC, Raggio DP, Bönecker MJS. Epidemiological study of traumatic dental injuries in 5-to 6-yearold Brazilian children. Braz Oral Res. 2015;29(1):1-6.

19. Firmino RT, Siqueira MBLD, VieiraAndrade RG, Gomes GB, Martins CC, Paiva $\mathrm{SM}$, et al. Prediction factors for failure to seek treatment following traumatic dental injuries to primary teeth. Braz Oral Res. 2014;28(1):1-7. 
20. Soares, FC, Cardoso, M, Bolan, M. Association between trauma to primary incisors and crown alterations in permanent successors. Braz Dent J. 2014;25(4):332-5.

21. Piva F, Pötter IG, Sari GT, Klein-Júnior CA, Coelho-de-Souza FH. Atendimento de urgência frente ao traumatismo alvéolo dentário: relato de caso clínico. Rev Assoc Paul Cir Dent. 2013;67(4):272-7.

22. Andreasen JO; Andreasen F M. Textbook and color atlas of traumatic injuries to the teeth. 3th ed. Copenhagen: Mosby, 1994.
23. da Silva LCA, de Oliveira Musse J, de Almeida AHDV, Marques JAM, Costa MCO. Injúrias dentárias traumáticas em crianças e adolescentes vítimas de violência periciadas no Instituto Médico Legal de Feira de Santana, Bahia. Rev Facul Odonto Univ Passo Fundo. 2016;21(1):31-6.

24. Carvalho ACDR, Barros SGD, Alves, Gurgel CA. Maus-tratos: estudo através da perspectiva da delegacia de proteção à criança e ao adolescente em Salvador, Bahia. Cien Saude Colet. 2009; 14:539-46.

\section{Correspondência para:}

Alessandra Castro Alves

e-mail: acastroalves@hotmail.com

Av. Araújo Pinho, 62 - Canela

40110-040 Salvador/BA 